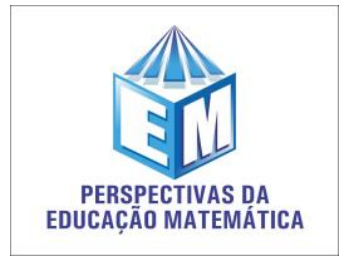

\author{
REVISTA DO PROGRAMA DE PÓS-GRADUAÇÃO \\ EM EDUCAÇÃO MATEMÁTICA DA UNIVERSIDADE \\ FEDERAL DE MATO GROSSO DO SUL (UFMS)
}

ISSN 2359-2842 Volume 14, número 36 - 2021 DOI: 10.46312/pem.v14i36.13066

\title{
Leitura de Tabela de Distribuição de Frequência por Estudantes do $6^{\circ}$ Ano
}

\section{Reading of Frequency Distribution Table by Students 6th}

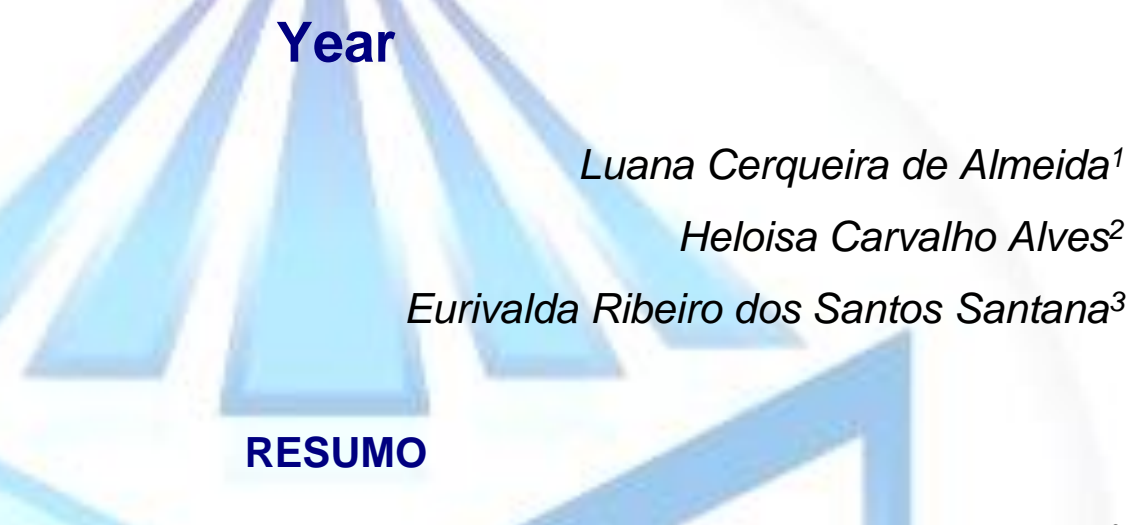

O presente artigo tem por objetivo analisar as respostas de atividades realizadas por estudantes do $6^{\circ}$ ano do Ensino Fundamental com vistas a identificar o nível de leitura de tabelas. A pesquisa é de abordagem qualitativa, realizada com estudantes da escola pública e foi analisada uma questão com dois itens. Em um item foi solicitado ao estudante a continuação do preenchimento de uma tabela enquanto no outro item foi requerida a leitura da tabela do item anterior. Analisamos as resoluções de 314 estudantes. Teoricamente, nos aportamos no componente cognitivo proposto para o Letramento Estatístico (GAL, 2002) e nos níveis de leitura de tabela de Wainer (1995). Os resultados indicam que $57,51 \%$ dos estudantes envolvidos na pesquisa, não conseguem alcançar o Nível Elementar de leitura de tabelas.

PALAVRAS-CHAVE: Letramento Estatístico. Tabela. Tratamento da Informação

\section{ABSTRACT}

The aim of this article is to analyze the resolution of problem situations carried out by students in the 6 th year of middle school in order to identify tables' reading. The research is qualitative, realized with students public schools. For this purpose, a question with two items was analyzed in which the student was required to complete and read a table. We analyzed the resolutions of 314 students. Theoretically, we focus on the cognitive component proposed for Statistical Literacy and table reading

1 Universidade Estadual do Sudoeste da Bahia. E-mail: luanacara@gmail.com. ORCID: https://orcid.org/0000-0001-6858-627X.

2 Universidade Estadual de Santa Cruz. E-mail: hcalves.Ima@uesc.br. ORCID: https://orcid.org/00000002-7813-0206.

3 Universidade Estadual de Santa Cruz. E-mail: eurivalda@hotmail.com. ORCID: https://orcid.org/0000-0001-6156-1205.

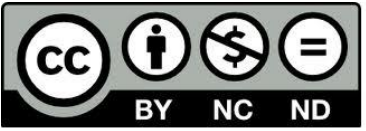

https://periodicos.ufms.br/index.php/pedmat/index

perspectivas.educacaomatematica@gmail.com 
levels. The results show that $57.51 \%$ of the students involved in the research are unable to reach the Elementary Level of table reading.

KEYWORDS: Statistical Literacy. Table. Treatment of Information.

\section{Introdução}

As pessoas recebem informações estatísticas, a todo tempo, por meio de diferentes veículos de informações como a televisão, jornais impressos, jogos, propagandas eleitorais, anúncios e redes sociais. Esses dados estatísticos são representados em forma de texto, por meio de símbolos e, também, por representações gráficas e tabulares. Portanto, para se posicionar criticamente, com relação a esses dados, na sociedade, compreender tais representações é elemento importante. Nesse contexto, o ensino de estatística foi incorporado, há algumas décadas, de forma generalizada em todos os níveis de ensino (BATANERO, 2002, SOUZA, LOPES, SOUZA, 2015).

A estatística, pela sua funcionalidade de transmitir informações de maneira suscinta, está presente no cotidiano do cidadão. Assim, a escola precisa fornecer condições para que os estudantes compreendam as informações que lhes são apresentadas. Nessa direção, desde a década de 90, a educação básica brasileira inseriu em seus documentos oficiais, como os Parâmetros Curriculares Nacionais (PCN), a necessidade do ensino de conteúdos estatísticos enfatizando, assim, a importância deles para a formação cidadã. $O$ que se deu graças "à crescente conscientização de sua importância na construção de um conjunto de ferramentas para a análise crítica de mundo" (COUTINHO; SPINA, 2015, p. 2). É importante ressaltar que o papel de destaque que a estatística desempenha no mundo contemporâneo, tratar dados não é mais suficiente. Além de saber ler, é preciso interpretar e se posicionar criticamente em relação às informações apresentadas.

Nessa direção, "a sobrevivência na sociedade depende cada vez mais de conhecimento, pois diante da complexidade da organização social, a falta de recursos para obter e interpretar informações, impede a participação efetiva e a tomada de decisões em relação aos problemas sociais" (BRASIL, 1998, p. 26). Então, o ensino de estatística tornou-se importante para o desenvolvimento dos cidadãos, visto que os mesmos estão envoltos em elementos e informações postas estatisticamente, e os avanços científicos e tecnológicos requerem novas habilidades do estudante para o mercado de trabalho.

A Base Nacional Comum Curricular - BNCC assegura o ensino de Estatística para o ensino fundamental, trazendo avanços em relação aos PCN no que diz 
respeito aos conceitos abordados. Na BNCC uma das habilidades da unidade temática Probabilidade e Estatística para o 6ํㅡㅁ ano do Ensino Fundamental, se refere a "Interpretar e resolver situações que envolvam dados de pesquisas sobre contextos ambientais, sustentabilidade, trânsito, consumo responsável, entre outros, apresentadas pela mídia em tabelas e em diferentes tipos de gráficos e redigir textos escritos com o objetivo de sintetizar conclusões" (BRASIL, 2018, p. 305). Evidenciando o objetivo do trabalho com conceitos estatísticos para a vivência na sociedade e para a formação do cidadão.

Nesse contexto de importância para a formação cidadã, foi desenvolvido nos anos de 2018 e 2019 o projeto de pesquisa "Desenvolvimento profissional de professores que ensinam matemática" que teve como objetivo investigar as experiências de aprendizagens de professores que ensinam Matemática no Ensino Fundamental, no âmbito de um grupo colaborativo, visando o seu desenvolvimento profissional e, tem como objeto matemático, os conceitos fundamentais da Estatística. Inicialmente, foi desenvolvido um instrumento diagnóstico, em forma de tarefa, para ser respondido por estudantes do $1^{\circ}$ ao $9^{\circ}$ do Ensino Fundamental, alunos dos professores colaboradores do projeto.

O presente estudo tem por objetivo analisar as respostas de atividades realizadas por estudantes do 6을 ano do Ensino Fundamental com vistas a identificar o nível de leitura de tabelas. Assim sendo, na próxima seção trataremos do letramento estatístico e os níveis de leitura de tabelas que fundamentaram a pesquisa realizada.

\section{O Letramento Estatístico e os Níveis de Leitura de Tabelas}

Ao se pensar no conhecimento estatístico que o estudante precisa aprender, há uma variedade de expressões que diferentes autores apresentam, como "statical literacy", "conhecimento estatístico", "saberes estatísticos", "letramento estatístico". Apesar de haver divergências em suas definições, não sendo objetivo deste artigo discuti-las, em "todas elas compartilham a necessidade atual de que os cidadãos são capazes de lidar com vários tipos de informações estatísticas e suas representações que são apresentadas a eles por diferentes mídias e em diferentes contextos de sua vida (ARTEAGA et. al, 2011, p. 58, tradução nossa) ${ }^{4 \prime}$.

\footnotetext{
${ }^{4}$ Trecho do original: "todos comparten la necesidad actual de que los ciudadanos sean capaces de tratar con diversos tipos de informaciones estadísticas y sus representaciones que se les presentan por distintos medios de comunicación y en distintos contextos de su vida" (ARTEAGA et. al, 2011, p. $58)$.
} 
Assim, trazemos o pensamento de Gal (2002), para o qual, o letramento estatístico refere-se, em termos gerais, a dois componentes inter-relacionados: o cognitivo e o disposicional. O cognitivo está ligado a capacidade das pessoas de interpretar e avaliar criticamente as informações estatísticas, argumentos ou fenômenos estocásticos, que eles podem encontrar em diversos contextos. E, O componente disposicional que se refere a capacidade do indivíduo discutir ou comunicar suas reações diante das informações estatísticas, tais como a sua compreensão do significado da informação, as suas opiniões sobre as implicações das informações, ou as suas preocupações quanto à aceitabilidade de determinadas conclusões, correspondendo às atitudes, crenças e postura crítica dessas pessoas diante das informações.

Esse autor organizou esses componentes por elementos, o componente cognitivo é composto por cinco elementos que são o letramento, o conhecimento estatístico, o conhecimento matemático, o conhecimento de contexto e a capacidade de formular questões críticas e; o componente disposicional que é composto por dois elementos, a postura crítica e as crenças e atitudes.

Gal (2002) argumenta que, dentre os elementos cognitivos há o conhecimento estatístico, no qual, a construção e a leitura de tabela é um desses conhecimentos. A interpretação da tabela requer não apenas familiaridade básica com médias e percentagens, mas habilidades de alfabetização e acesso a diferentes tipos de conhecimento. Uma tabela é para comunicação, não para armazenamento de dados (WAINER,1995).

Segundo Cazorla et. al. (2017, p. 48) "uma tabela é qualquer organização matricial composta por linhas, colunas, cujas interseções são denominadas de células, onde se encontram os dados, que podem ser números, categorias, palavras, frases, etc.". Se uma tabela apresentar os dados por meio de frequências, esta é chamada Tabela de Distribuição de Frequência (TDF) que para Triola (2005, p. 623) é a "lista das categorias de valores juntamente com suas frequências correspondentes".

Uma TDF é organizada por meio de variáveis. Segundo Cazorla e Oliveira (2010, p. 120) variável "é uma característica da população (ou amostra) em estudo, possível de ser medida, contada ou categorizada". Elas podem ser classificadas de acordo com a natureza de seus resultados, podendo ser qualitativa ou quantitativa.

As variáveis qualitativas são aquelas cujo resultados são categorias que denotam uma qualidade. Elas podem ser de dois tipos: ordinal, quando é passível de 
uma ordenação, por exemplo, nível de instrução e gosto por animais; e nominal, são aquelas em que não há uma ordenação, por exemplo, gênero e cor da pele (CAZORLA; OLIVEIRA, 2010).

As variáveis quantitativas são aquelas cujos resultados fornecem quantidades passíveis de contagem e mensuração. As passíveis de contagem são ditas discretas, a exemplo, quantidade de cadeiras e número de irmãos; as resultantes de mensuração são tidas como contínuas, a exemplo, peso e distância (CAZORLA; OLIVEIRA, 2010).

No que diz respeito a leitura e interpretação de dados apresentados em tabelas, Wainer (1995) propôs três níveis, a saber: Nível Elementar, que se refere à capacidade do indivíduo em extrair das tabelas, dados pontuais, sem exigir qualquer ação de comparação ou de análise dos mesmos. Nível Intermediário, que implica interpolar e descobrir quais são as relações existentes entre os dados que são mostrados nas tabelas. Nível avançado, que envolve uma compreensão mais ampla da estrutura dos dados apresentados em sua totalidade, geralmente comparando tendências e analisando relações implícitas nas tabelas.

O leitor em nível intermediário ao ler uma tabela é claramente diferente do leitor em nível elementar, uma leitura que necessita identificar relações requer a noção de conectividade. O nível avançado requer leituras implícitas, sendo necessário realizar leituras para além do que está posto na tabela.

Para que o cidadão possa se posicionar e tomar decisões pautadas em fatos e dados reais, é preciso ter um nível de compreensão dos fatos e informações que os possibilitem estar no nível avançado proposto por Wainer (1995). Mas, para chegar a esse nível é necessário passar pelos anteriores e, fatores como a idade e maturação influenciam diretamente para que esse avanço seja possível. Ao analisar as habilidades da unidade temática Probabilidade e Estatística propostas pela BNCC (2019) para os estudantes do $6^{\circ}$ ano espera-se que se encontrem na transição do nível elementar para o nível intermediário.

No que diz respeito ao letramento estatístico, a leitura de tabelas é um dos fatores necessários para que o indivíduo possa vir a ter essa competência. Com esse pensamento é que analisamos os dados deste estudo.

Se aportando no letramento estatístico e nos níveis de leitura de tabelas, na próxima seção trataremos da Metodologia da pesquisa que gerou este artigo.

\section{Metodologia}


A pesquisa é de abordagem qualitativa, nela analisou-se as resoluções feitas pelos estudantes. De acordo com Yin (2016, p. 29) "em vez de tentar chegar a uma definição singular de pesquisa qualitativa, você pode considerar cinco características", uma dessas características é representar as opiniões e perspectivas das pessoas de um estudo e, neste texto, nos propomos a analisar as questões a partir das perspectivas dos estudantes. Ela faz parte do projeto de pesquisa intitulado "Desenvolvimento profissional de professores que ensinam matemática" e envolveu três escolas, 43 turmas e 933 estudantes que estavam cursando do 60 ao 9o ano do Ensino Fundamental, ver Tabela 1. As escolas eram públicas, localizadas na região sul da Bahia. O referido projeto de pesquisa seguiu todos os procedimentos éticos prescritos, tais como a assinatura do Termo de Consentimento Livre e Esclarecido (TCLE), autorização da direção da escola, dentre outros.

Tabela 1 - Número de estudantes envolvidos na pesquisa por ano escolar

\begin{tabular}{|c|c|c|c|c|c|c|c|c|}
\hline \multirow[b]{2}{*}{$\begin{array}{l}\text { Ano } \\
\text { escolar }\end{array}$} & \multicolumn{2}{|c|}{ Escola A } & \multicolumn{2}{|c|}{ Escola B } & \multicolumn{2}{|c|}{ Escola C } & \multicolumn{2}{|l|}{ Total } \\
\hline & \begin{tabular}{|l|}
$№$ de \\
turmas
\end{tabular} & \begin{tabular}{|l|}
$№$ de \\
estudantes
\end{tabular} & $\begin{array}{l}\text { № de } \\
\text { turmas }\end{array}$ & $\begin{array}{l}№ \text { de } \\
\text { estudantes }\end{array}$ & $\begin{array}{l}\text { № de } \\
\text { turmas }\end{array}$ & $\begin{array}{l}№ \text { de } \\
\text { estudantes }\end{array}$ & $\begin{array}{l}\text { № de } \\
\text { turmas }\end{array}$ & $\begin{array}{l}№ \text { de } \\
\text { estudantes }\end{array}$ \\
\hline $6^{\circ}$ ano & 4 & 46 & 5 & 147 & 6 & 121 & 15 & 314 \\
\hline $7^{\circ}$ ano & 3 & 41 & 4 & 114 & 5 & 93 & 12 & 248 \\
\hline $8^{\circ}$ ano & 2 & 28 & 4 & 118 & 4 & 76 & 10 & 222 \\
\hline $9^{\circ}$ ano & 1 & 18 & 3 & 74 & 2 & 57 & 6 & 149 \\
\hline Total & 10 & 133 & 16 & 453 & 17 & 347 & 43 & 933 \\
\hline
\end{tabular}

Fonte: Material produzido no GPEMEC (2018-2019).

Observamos na Tabela 1 que o $6^{\circ}$ ano é o ano escolar que tem mais turmas e, consequentemente, mais estudantes, assim analisamos o desempenho e as resoluções dos 314 estudantes, do referido ano escolar, que responderam à Questão 3 de um instrumento diagnóstico elaborado com quatro questões. A escolha deste ano escolar se justifica por ser esse o primeiro dos anos finais do Ensino Fundamental e nele o PCN indica como conteúdo do bloco Tratamento da Informação a "leitura e interpretação de dados expressos em tabelas e gráficos" (BRASIL, 1998, p.74), bem como é indicado na BNCC como um dos objetos de conhecimento a "leitura e interpretação de tabelas e gráficos (de colunas ou barras simples ou múltiplas) referentes a variáveis categóricas e variáveis numéricas" (BRASIL, 2019, p. 304). Os participantes foram alunos dos professores que fazem parte do projeto de pesquisa e que estiveram presentes no dia da realização desse 
diagnóstico. Os protocolos, aqui apresentados, trarão nomes fictícios para os estudantes buscando respeitar a sua identidade.

$O$ instrumento foi delineado de forma a acompanhar o desempenho dos estudantes com conceitos estatísticos ao longo dos quatro últimos anos escolares do Ensino Fundamental e, ao mesmo tempo, considerou as orientações dos PCN para os anos escolares que os estudantes estavam cursando. $O$ instrumento foi baseado nos PCN pois durante o desenvolvimento do instrumento para coleta de dados a BNCC ainda não estava implementada.

Neste estudo, temos, como categorias de análise, o desempenho e as resoluções adotadas pelos estudantes do $6^{\circ}$ ano nos itens a e b da Questão 3 , que segue apresentada no Figura 1.

Figura 1 - Estrutura da Questão 3

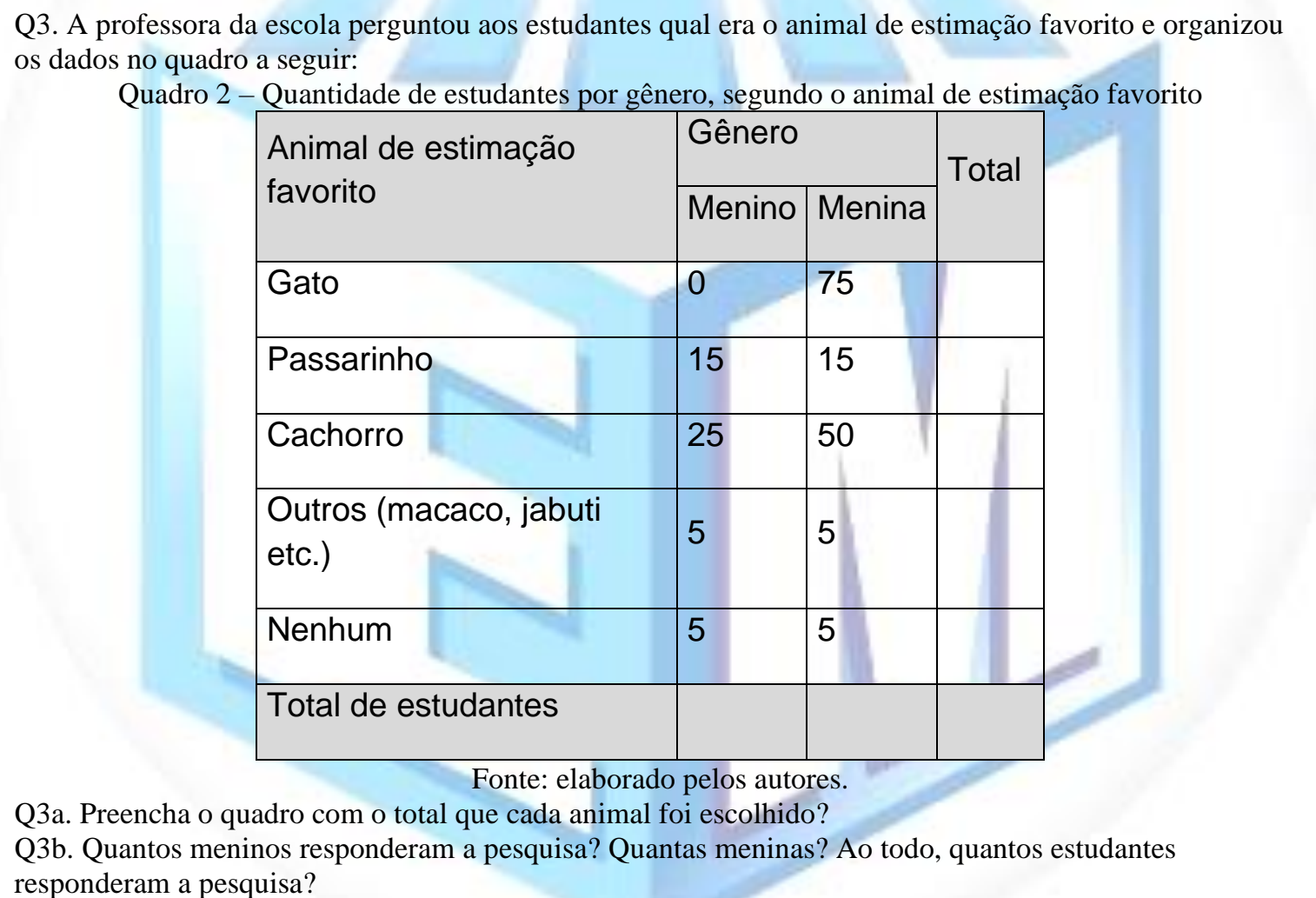

responderam a pesquisa?

Fonte: Material produzido no GPEMEC (2018-2019).

A Questão 3 trata uma variável de natureza qualitativa nominal (animal de estimação favorito), o campo numérico é da ordem das centenas (valor máximo 200), os valores são inteiros e a representação estatística é uma Tabela de Distribuição de Frequência. Para sua resolução o estudante necessita mobilizar conhecimentos da estrutura aditiva ao precisar somar os valores das linhas e das colunas. A tabela utilizada na Questão 3 foi nomeada, no instrumento do estudante, como Quadro 2, mas, para nossa análise, referimo-nos à mesma, exclusivamente, 
como tabela ${ }^{5}$. Nessa questão, será observado o componente cognitivo proposto por Gal (2002), mais especificamente o conhecimento estatístico e matemático.

O item Q3a solicitava que o estudante fosse capaz de identificar o número total de estudantes por linha em uma tabela de dupla entrada. Esperava-se que somasse o total de meninas e de meninos por linha, conforme a escolha do animal favorito.

O item Q3b solicitava que fosse capaz de identificar o número total de estudantes por coluna e o total de estudantes. Era esperado que identificasse os totais em cada gênero e o total de estudantes participantes da pesquisa fazendo a soma dos valores da última coluna ou ao somar o total de meninos e meninas na última linha.

Na questão 3 analisamos se o desempenho do estudante o classifica no Nível elementar proposto por Wainer (1995), pois a questão não apresenta elementos que dê condições de analisar os demais níveis.

A realização da atividade foi feita pelo professor de cada turma, a quem foi solicitado não interferir nas respostas dos estudantes, pois o objetivo era identificar os saberes prévios deles. $\mathrm{O}$ instrumento foi distribuído no coletivo de cada turma e respondido pelos estudantes individualmente.

Para a análise foram criadas as categorias dispostas no Quadro 1 cuja descrição emergiu das resoluções feitas pelos estudantes nos protocolos.

Quadro 1 - Categorias de análise das resoluções

\begin{tabular}{|c|c|c|c|c|c|}
\hline $\begin{array}{l}\text { Item da } \\
\text { questão }\end{array}$ & $\begin{array}{l}\text { Categoria de } \\
\text { desempenho }\end{array}$ & $\begin{array}{l}\text { Categorias dos } \\
\text { esquemas de } \\
\text { resolução }\end{array}$ & Descrição & $\begin{array}{l}\text { Categoria de } \\
\text { pertinência no nível } \\
\text { elementar de leitura } \\
\text { e interpretação de } \\
\text { tabela }\end{array}$ & Descrição \\
\hline \multirow{4}{*}{ Q3a } & Certo & & $\begin{array}{l}\text { O total de cada } \\
\text { linha foi } \\
\text { respondido } \\
\text { correto }\end{array}$ & & - \\
\hline & \multirow{2}{*}{ Errado } & $\begin{array}{l}\text { Totalmente } \\
\text { errada }\end{array}$ & $\begin{array}{l}\text { O total de cada } \\
\text { linha foi } \\
\text { respondido } \\
\text { errado } \\
\end{array}$ & - & - \\
\hline & & $\begin{array}{l}\text { Parcialmente } \\
\text { errada }\end{array}$ & $\begin{array}{l}\text { Houve linhas } \\
\text { com total correto } \\
\text { e linhas com total } \\
\text { errado }\end{array}$ & - & - \\
\hline & Branco & - & $\begin{array}{l}\text { Não houve } \\
\text { registro de } \\
\text { resposta }\end{array}$ & - & - \\
\hline Q3b & Certo & Resposta certa & A resposta & Pertinência no nível & Coletou os \\
\hline
\end{tabular}

\footnotetext{
${ }^{5}$ Um quadro é uma organização matricial em que não necessariamente haverá tratamento dos dados nele apresentado, enquanto a tabela está relacionada aos dados já tratados.
} 


\begin{tabular}{|c|c|c|c|c|}
\hline & & estava correta & elementar & $\begin{array}{l}\text { dados da } \\
\text { tabela }\end{array}$ \\
\hline \multirow{3}{*}{ Errado } & $\begin{array}{l}\text { Resposta } \\
\text { errada e } \\
\text { diferente da } \\
\text { tabela }\end{array}$ & $\begin{array}{l}\text { A resposta } \\
\text { estava errada e } \\
\text { diferente do que } \\
\text { estava presente } \\
\text { na tabela }\end{array}$ & $\begin{array}{l}\text { Não pertinência no } \\
\text { nível elementar }\end{array}$ & $\begin{array}{l}\text { Não coletou } \\
\text { os dados da } \\
\text { tabela }\end{array}$ \\
\hline & $\begin{array}{l}\text { Resposta } \\
\text { errada e igual a } \\
\text { tabela }\end{array}$ & $\begin{array}{l}\text { A resposta } \\
\text { estava errada e } \\
\text { igual ao que } \\
\text { estava presente } \\
\text { na tabela }\end{array}$ & $\begin{array}{l}\text { Pertinência no nível } \\
\text { elementar }\end{array}$ & $\begin{array}{l}\text { Coletou os } \\
\text { dados da } \\
\text { tabela }\end{array}$ \\
\hline & $\begin{array}{l}\text { Resposta } \\
\text { errada sem } \\
\text { responder a } \\
\text { tabela }\end{array}$ & $\begin{array}{l}\text { Apresentou uma } \\
\text { resposta errada e } \\
\text { a tabela estava } \\
\text { em branco }\end{array}$ & $\begin{array}{l}\text { Não pertinência no } \\
\text { nível elementar }\end{array}$ & $\begin{array}{l}\text { Não coletou } \\
\text { os dados da } \\
\text { tabela }\end{array}$ \\
\hline Branco & $\begin{array}{l}\text { Resposta em } \\
\text { branco }\end{array}$ & $\begin{array}{l}\text { Não houve } \\
\text { registro }\end{array}$ & $\begin{array}{l}\text { Não pertinência no } \\
\text { nível elementar }\end{array}$ & \\
\hline
\end{tabular}

Fonte: Elaborado pelas autoras (2021).

As categorias de análise dos esquemas de resolução dos estudantes, emergiram da análise das respostas dadas. Ressaltamos que não foi feita entrevista com os estudantes, o que não nos possibilita fazer inferências em relação aos esquemas não explícitos nas respostas dadas no instrumento.

Em relação a pertinência ou não no nível elementar de leitura e interpretação proposto por Wainer (1995), classificamos respostas corretas e incorretas. A escolha das incorretas se justifica por considerarmos que os estudantes erraram ao efetuar 0 total das linhas ou da coluna no item Q3a e, responderam no item Q3b conforme o que preencheu na tabela. Configurando-se a leitura e interpretação da tabela corretamente, pois o estudante conseguiu coletar da tabela os dados.

\section{Discussão dos Resultados}

Apresentamos, a seguir, o desempenho e as respostas realizadas pelos estudantes ao resolverem a questão. Para tanto, dividimos a análise em dois momentos: o desempenho e as resoluções, e organizamos por itens, Q3a e Q3b. Como no item Q3b há três perguntas as chamaremos de Q3b1, Q3b2 e Q3b3 ao nos referirmos as respostas desse item. A Tabela 2 apresenta o desempenho dos estudantes no item Q3a, em que era solicitado o total, por linha, de animais escolhidos. 
Tabela 2 - Desempenho dos estudantes no item Q3a

\begin{tabular}{ll}
$\begin{array}{l}\text { Categoria de } \\
\text { Desempenholitem }\end{array}$ & Q3a \\
\hline Certo & $51,44 \%$ \\
\hline Errado & $20,76 \%$ \\
\hline Branco & $27,80 \%$ \\
\hline Total & $100 \%$
\end{tabular}

Fonte: Material produzido no GPEMEC (2018-2019).

$\mathrm{Na}$ Tabela 2 é possível observar que mais da metade $(51,44 \%)$ dos estudantes acertaram o item Q3a, 20,76\% erraram e os demais (27,80\%) deixaram em branco, indicando que mais da metade dos estudantes conseguiu fazer a adição dos valores dados por linha. Esses dados, mesmo com percentual de acerto maior que $50 \%$ são preocupantes, pois desde 1998, nos PCN, é indicado que os estudantes construam procedimentos para coletar, organizar e comunicar dados, utilizando tabelas e, quase metade dos estudantes investigados demonstraram, ainda, não conseguir preencher dados em uma tabela. Considerando que, além disso, tabelas desse tipo estão presentes nos livros didáticos de Matemática, Geografia e Ciências analisamos as resoluções apresentadas pelos estudantes, buscando compreender as resoluções feitas.

Apresentamos na Figura 2 a resolução do estudante Igor, que se configura num exemplo das resoluções que foram categorizadas como corretas.

Figura 2- Resolução correta ao item Q3a feita por Igor

Quadro 2 - Quantidade de estudantes por gênero, segundo o animal de estimaçāo favorito

\begin{tabular}{|l|c|c|c|}
\hline \multirow{2}{*}{$\begin{array}{l}\text { Animal de estimação } \\
\text { favorito }\end{array}$} & \multicolumn{2}{|c|}{ Gênero } & Total \\
\cline { 2 - 4 } & Menino & Menina & \\
\hline Gato & 0 & 75 & 75 \\
\hline Passarinho & 15 & 15 & 3 \\
\hline Cachorro & 25 & 50 & 75 \\
\hline Outros (macaco, jabuti etc.) & 5 & 5 & 10 \\
\hline Nenhum & 5 & 5 & 10 \\
\hline Total de estudantes & 50 & 190 & 0 \\
\hline
\end{tabular}

Fonte: elaborado pelos autores.

Fonte: Material do projeto de pesquisa (2018-2019).

Percebe-se que os valores colocados na coluna referente ao total, correspondem a soma do quantitativo dos gêneros. Essa resolução foi utilizada por $51,44 \%$ dos estudantes o que equivale a 161 estudantes. Inferimos que para essa resolução o estudante precisava fazer a leitura das informações apresentadas na tabela e mobilizar conhecimentos matemáticos para efetuar as operações, elementos que compõem o componente cognitivo que, segundo Gal (2002), compõe 
o letramento estatístico, além de ser uma habilidade esperada dos cidadãos. Assim, considerando que a leitura de tabelas é um passo para alcançar tal letramento e, mesmo ultrapassando $50 \%$ a quantidade de estudantes que utilizaram essa resolução, esse é um quantitativo baixo, visto que, é esperado nesse ano de escolaridade, que o estudante construa essas habilidades, como sugerido pela BNCC desde o $2^{\circ}$ ano do Ensino Fundamental.

A Figura 3 apresenta a resolução do estudante Carlos classificada na categoria errada considerada como totalmente errada.

Figura 3 - Resolução para Q3a totalmente errada feita pelo estudante Carlos Quadro 2 - Quantidade de estudantes por gênero, segundo o animal de estimaçăo favorito

\begin{tabular}{|l|c|c|c|}
\hline \multirow{2}{*}{$\begin{array}{l}\text { Animal de estimação } \\
\text { favorito }\end{array}$} & \multicolumn{2}{|c|}{ Gênero } & \multirow{2}{*}{ Total } \\
\cline { 2 - 4 } & Menino & Menina & \\
\hline Gato & 0 & 75 & 6 \\
\hline Passarinho & 15 & 15 & \\
\hline Cachorro & 25 & 50 & \\
\hline Outros (macaco, jabuti etc.) & 5 & 5 & 2 \\
\hline Nenhum & 5 & 5 & \\
\hline Total de estudantes & & & \\
\hline
\end{tabular}

Fonte: Material do projeto de pesquisa (2018-2019).

A Figura 3, apresenta a resolução de Carlos, em que os valores das somas de todas as linhas estão errados e não fez a adição das quantidades por coluna. Nos totais apresentados, por linha, não conseguimos identificar relação com as quantidades referentes ao animal de estimação preferido dos meninos e das meninas. Inferimos que os estudantes, que utilizaram esse tipo de resposta, não demonstraram conhecimento estatístico necessários para a resolução da questão, sendo esses, elementos cognitivos propostos por Gal (2002) como componentes cognitivos do letramento estatístico. Não conseguimos fazer inferências sobre os possíveis esquemas que os estudantes poderiam ter mobilizado para esse tipo de resolução, logo nada podemos falar a respeito de seu conhecimento matemático. Esse procedimento de resolução foi apresentado por 4,5\% dos estudantes, equivalendo a 14 estudantes.

A Figura 4 apresenta a resolução do estudante Marcos, em que o erro foi categorizado como parcial. 
Figura 4 - Resolução em Q3a com erro parcial feita por Marcos

Quadro 2-Quantidade de estudantes por gênero, segundo o animal de

estimação favorito

\begin{tabular}{|l|c|c|c|}
\hline \multirow{2}{*}{$\begin{array}{l}\text { Animal de estimaçáo } \\
\text { favorito }\end{array}$} & \multicolumn{2}{|c|}{ Gênero } & Total \\
\hline Gato & 0 & 75 & 75 \\
\hline Passarinho & 15 & 15 & 30 \\
\hline Cachorro & 25 & 50 & 65 \\
\hline Outros (macaco, jabuti etc.) & 5 & 5 & 10 \\
\hline Nenhum & 5 & 5 & 70 \\
\hline
\end{tabular}

Total de estudantes

Fonte: elaborado pelos autores.

Fonte: Material do projeto de pesquisa (2018-2019).

Na resolução apresentada na Figura 4, na linha referente ao total de cachorro foi registrada a soma 65 , enquanto o correto seria 75 . No entanto, ao acertar os valores referente as demais linhas, o estudante demonstra ter compreendido o que foi solicitado pelo enunciado da questão, ou seja, conseguiu ler os dados da tabela. Esse tipo de solução foi apresentado por 51 estudantes, que equivale a 16,3\%.

A Tabela 3 apresenta o desempenho dos estudantes no item Q3b.

Tabela 3 - Desempenho dos estudantes no item Q3b

\begin{tabular}{|c|c|c|c|}
\hline $\begin{array}{c}\text { Categoria de } \\
\text { Desempenholitem }\end{array}$ & Q3b1 & Q3b2 & Q3b3 \\
\hline Certo & $37,70 \%$ & $31,63 \%$ & $25,88 \%$ \\
\hline Errado & $43,76 \%$ & $48,88 \%$ & $50,47 \%$ \\
\hline Branco & $18,54 \%$ & $19,49 \%$ & $23,65 \%$ \\
\hline Total & $100,00 \%$ & $100,00 \%$ & $100,00 \%$ \\
\hline
\end{tabular}

No que diz respeito ao acerto, o maior valor foi no item Q3b1 (37,7\%), em que era solicitado a quantidade de meninos que responderam a pesquisa, havendo decréscimo do desempenho nos itens Q3b2 e Q3b3, que diz respeito a quantidade de meninas e a quantidade de estudantes no total, respectivamente. Nesse item era solicitado que os estudantes lessem o total por coluna e o total de estudantes para que analisássemos a capacidade de leitura de tabela dos estudantes. A Tabela 4 apresenta a percentagem dos estudantes nesse item, por pertinência e esquema de resolução. 
Tabela 4 - Pertinência e esquema de resolução dos estudantes no item Q3b

\begin{tabular}{lllll}
\hline Pertinência & Esquema de resoluçãoVItem & $\mathbf{Q 3 b 1}$ & $\mathbf{Q 3 b 2}$ & $\mathbf{Q 3 b 3}$ \\
\hline Pertinência no nível & Resposta certa & $37,70 \%$ & $31,63 \%$ & $25,88 \%$ \\
\cline { 2 - 5 } elementar & Resposta errada e igual a tabela & $4,79 \%$ & $7,99 \%$ & $3,51 \%$ \\
\hline \multirow{3}{*}{$\begin{array}{l}\text { Não pertinência no nível } \\
\text { elementar }\end{array}$} & $\begin{array}{l}\text { Resposta errada e diferente da } \\
\text { tabela }\end{array}$ & $4,47 \%$ & $3,83 \%$ & $4,79 \%$ \\
\cline { 2 - 5 } & $\begin{array}{l}\text { Resposta errada sem responder a } \\
\text { tabela }\end{array}$ & $34,50 \%$ & $37,06 \%$ & $42,17 \%$ \\
\cline { 2 - 5 } & Resposta em branco & $18,54 \%$ & $19,49 \%$ & $23,65 \%$ \\
\hline Total & & $100,00 \%$ & $100,00 \%$ & $100,00 \%$ \\
\hline
\end{tabular}

Fonte: Material produzido no GPEMEC (2018-2019).

Tanto os estudantes que acertaram, quanto os que apresentaram o valor errado na tabela, demonstraram estar no nível elementar proposto por Wainer (1995), pois extraíram da tabela dados pontuais, havendo pertinência em suas respostas. Os estudantes que apresentaram resposta errada e igual a tabela, mesmo errando no momento do preenchimento da tabela, realizaram a leitura adequada. Tal situação nos permite afirmar que $37,17 \%$ das respostas esperadas para o total dos três itens (a média percentual do total de Q3b1, Q3b2 e Q3b3), demonstram o nível elementar de leitura de tabela, o que indica que a maioria dos estudantes ainda não construiu os conhecimentos necessários para o nível elementar proposto por Wainer (1995). A seguir apresentamos as resoluções para cada um dos desses itens de Q3, conforme as categorias de análise.

A Figura 5 apresenta a resolução da estudante Maria, um exemplo de uma resposta certa do item Q3b.

Figura 5 - Resolução com acerto no item Q3b feita por Maria

Q3. A professora da escola perguntou aos estudantes qual era o animal de estimação favorito e organizou os dados no quadro a seguir:

Quadro 2 - Quantidade de estudantes por gênero, segundo o animal de estimaçăo favorito

\begin{tabular}{|l|c|c|c|}
\hline \multirow{2}{*}{$\begin{array}{l}\text { Animal de estimaçäo } \\
\text { favorito }\end{array}$} & \multicolumn{2}{|c|}{ Género } & Total \\
\hline Gato & 0 & 75 & 75 \\
\hline Passarinho & 15 & 15 & 30 \\
\hline Cachorro & 25 & 50 & 75 \\
\hline Outros (macaco, jabuti etc.) & 5 & 5 & 70 \\
\hline Nenhum & 5 & 5 & 10 \\
\hline Total de estudantes & 50 & 150 & \\
\hline
\end{tabular}

Fonte: elaborado pelos autores.

Q3a. Preencha o quadro com o total que cada animal foi escolhido?

Q3b. Quantos meninos responderam a pesquisa? 50

Quantas meninas? 750

Ao todo, quantos estudantes responderam a pesquisa? 200

Fonte: Material do projeto de pesquisa (2018-2019).

Observa-se na Figura 5, que a estudante Maria resolveu as adições e respondeu as perguntas corretamente, o que indica compreensão do que estava 
sendo proposto na questão e pertinência ao nível elementar de leitura de tabela. Como os estudantes não deixaram registros das relações feitas para apresentarem esses valores como resposta, acredita-se que eles conseguem extrair de uma tabela os dados pontuais e com eles realizar as adições.

A Figura 6 apresenta a resolução da estudante Rita que respondeu as perguntas corretamente, mas se equivocou nas totalizações.

Figura 6 - Resolução com resposta errada e igual a tabela referente ao item Q3b feita por Rita

\begin{tabular}{|c|c|c|c|}
\hline $\begin{array}{l}\text { Animal de estimação } \\
\text { favorito }\end{array}$ & Gênero & Menina & Total \\
\hline Gato & 0 & 75 & 75 \\
\hline Passarinho & 15 & 15 & 30 \\
\hline Cachorro & 25 & 50 & 75 \\
\hline Outros (macaco, jabuti etc.) & 5 & 5 & 10 \\
\hline Nenhum & 5 & 5 & 10 \\
\hline Total de estudantes & $50:$ & 9402 & \\
\hline \multicolumn{4}{|c|}{$\begin{array}{l}\text { Q3a. Preencha o quadro com o total que cada animal foi escol } \\
\text { Q3b. Quantos meninos responderam a pesquisa? } 50\end{array}$} \\
\hline
\end{tabular}

Fonte: Material do projeto de pesquisa (2018-2019).

Na Figura 6, a estudante Rita apresentou, como resposta aos itens Q3b2 e Q3b3, somas erradas, porém mesmo a resposta estando errada ela estava igual a apresentada na tabela. A estudante colocou nos espaços do item Q3b as informações contidas na última linha da tabela. Esse procedimento ilustra como foram as resoluções registradas por estudantes classificados no nível elementar proposto por Wainer (1995), mesmo com as resoluções incorretas, consideramos pertinente com o nível elementar. O maior percentual de erro, nesta categoria, ocorreu para o item Q3b2 (7,9\%) e o menor percentual foi no item Q3b3 (3,5\%). Na Tabela 4, é possível observar que $65,1 \%$ dos estudantes deixaram em branco a célula, referente ao total no item Q3b3 (resposta errada sem responder a tabela e branco), esse fator pode ter influenciado para que o percentual de acerto deste item tenha sido menor, visto que mais de $65 \%$ dos estudantes não responderam.

A Figura 7 apresenta uma resolução em que as respostas não têm relação direta com os valores dados por gênero. 
Figura 7 - Resolução da Q3b com resposta errada e diferente da resposta escrita na tabela feita por Lucas

Q3. A professora da escola perguntou aos estudantes qual era o animal de estimaçăo favorito e organizou os dados no quadro a seguir:

Quadro 2-Quantidade de estudantes por gênero, segundo o animal de estimação favorito

\begin{tabular}{|l|c|c|c|}
\hline \multirow{2}{*}{$\begin{array}{l}\text { Animal de estimação } \\
\text { favorito }\end{array}$} & \multicolumn{2}{|c|}{ Género } & \multirow{2}{*}{ Total } \\
\cline { 2 - 3 } & Menino & Menina & \\
\hline Gato & 0 & 75 & 75 \\
\hline Passarinho & 15 & 15 & 3 \\
\hline Cachorro & 25 & 50 & 75 \\
\hline Outros (macaco, jabuti etc.) & 5 & 5 & 1 \\
\hline Nenhum & 5 & 5 & 1 \\
\hline Total de estudantes & & 5 & 26 \\
\hline
\end{tabular}

Fonte: elaborado pelos autores.

Q3a. Preencha o quadro com o total que cada animal foi escolhido?

Q3b. Quantos meninos responderam a pesquisa?

Quantas meninas?

Ao todo, quantos estudantes responderam a pesquisa? 09

Fonte: Material do projeto de pesquisa (2018-2019).

Percebe-se, na Figura 7, que as respostas apresentadas pelo estudante Lucas diferem do que fez nas adições por coluna, pois preencheu corretamente a tabela, mas o responder o item b apresentou respostas não relacionadas a última linha. Mas à quantidade de categorias que tiveram alguma escolha dos meninos (04) e das meninas (05).

Isso demonstra que não consegue realizar a leitura dos dados presentes em tabelas e, portanto, não pertinência ao nível elementar proposto por Wainer (1995), Esse tipo de resolução foi apresentado por $4,8 \%$ dos estudantes o que equivale a 15 estudantes (ver Tabela 4).

A Figura 8 apresenta a resolução da estudante Rute que deixou a linha da tabela referente ao total em branco e apresentou respostas erradas no item Q3b. 
Figura 8 - Resolução em que a resposta é errada sem responder a tabela no item Q3b feita por Rute

Q3. A professora da escola perguntou aos estudantes qual era o animal de estimação favorito e organizou os dados no quadro a seguir:

Quadro 2 - Quantidade de estudantes por gênero, segundo o animal de estimaçåo favorito

\begin{tabular}{|l|c|c|c|}
\hline \multirow{2}{*}{$\begin{array}{l}\text { Animal de estimação } \\
\text { favorito }\end{array}$} & \multicolumn{2}{|c|}{ Gênero } & \multirow{2}{*}{ Total } \\
\hline Gato & Menino & Menina & \\
\hline Passarinho & 0 & 75 & \\
\hline Cachorro & 15 & 15 & \\
\hline Outros (macaco, jabuti etc.) & 25 & 50 & \\
\hline Nenhum & 5 & 5 & \\
\hline Total de estudantes & & 5 & \\
\hline
\end{tabular}

Fonte: elaborado pelos autores.

Q3a. Preencha o quadro com o total que cada animal foi escolhido?

Q3b. Quantos meninos responderam a pesquisa?

Quantas meninas? 240 menens

Ao todo, quantos estudantes responderam a pesquisa? 380

Fonte: Material do projeto de pesquisa (2018-2019).

A porcentagem de estudantes que realizou este procedimento alcançou $42 \%$, esses estudantes erraram a resposta e, pode-se inferir que, sua resolução não foi retirada da tabela, visto que estava em branco e, não foi possível estabelecer relações entre os valores apresentados como respostas e os valores dados na tabela. Dessa forma, não há elementos para inferir sobre qual leitura foi feita para se encontrar tais resultados.

Pode-se afirmar que os três itens apresentam mesmo grau de dificuldade, pois o estudante precisava identificar os totais na última linha, referentes as três colunas. Contudo, as perguntas em cada item não se referem a expressão "total de estudantes", mas, "quantos", "quantas" e "ao todo, quantos estudantes", por serem expressões escritas de maneira diferente do que está na tabela pode ter influenciado no baixo desempenho. Diante dos resultados pode-se inferir que menos da metade dos estudantes participantes deste estudo se encontram no nível elementar de leitura de tabela proposto por Wainer (1995).

Isso é preocupante, pois a BNCC, indica para o 6ํan ano, que os estudantes sejam capazes de interpretar e resolver situações apresentadas em tabelas e sintetizem conclusões (BRASIL, 2019).

\section{Considerações Finais}

Neste estudo analisamos as resoluções de atividades realizadas por estudantes do 6ำ ano do Ensino Fundamental com vistas a identificar a leitura em 
tabelas. Os dados indicam que $57,51 \%$ dos estudantes envolvidos na pesquisa, não conseguem alcançar o Nível Elementar de leitura de tabelas em que se espera que o estudante tenha habilidade de extrair das tabelas, dados pontuais e, não solicita a ação de comparar dados ou de analisá-los.

As questões apresentadas aos estudantes não requeriam escritas textuais para interpretações dos dados, porque foi solicitado ler, interpretar e efetuar operações de adição para completar com as somas, frases que estavam prontas. Embora sejam habilidades prevista para o 6 ano de escolaridade, os resultados indicam que esses estudantes ainda não as desenvolvem para a construção do conhecimento leitura e interpretação de tabelas.

Os dados obtidos, ao serem balizados pelo que é recomendado pela BNCC e pelos $\mathrm{PCN}$, mostram que os alunos não alcançaram habilidades como: intepretação de dados e posicionamento frente às informações apresentadas em tabelas.

Em nossas análises identificamos que, para além da classificação em níveis de leitura de tabela, os estudantes revelam dificuldades em fazer adições na ordem das dezenas e na ordem das centenas. Resultados que estão na mesma direção de estudos realizados por Santana et al. (2016) e Santana, Cazorla e Santos (2019), o que indica a necessidade de intervenções que objetivem sanar tais dificuldades com estudantes do Ensino Fundamental.

Essa visão a respeito do desempenho dos estudantes nos remete a refletir a formação do professor, pois é preciso discutir esses resultados com professores e buscar estratégias de ensino que possibilitem minimizar essas dificuldades e aumentar os índices de desempenho dos estudantes. Assim, sugerimos que sejam feitos trabalhos investigativos em sala de aula com os estudantes. De modo que, se possibilite investigações pertinentes à realidade que ele está inserido ou use seus dados pessoais. Conduzindo a um maior engajamento no processo de coleta, de análise e de conclusão dos resultados, o que os possibilita ter mais propriedade e condições de ampliar as suas aprendizagens. O que pode os conduzir a melhores resultados e desempenho.

\section{Referências}

ARTEAGA, Pedro; BATANERO, Carmen; CANADAS, Gustavo; CONTRERAS, J. Miguel. Las Tablas y Gráficos Estadísticos como Objetos Culturales. Números, Revista de Didática de las Matemáticas. v. 76, 55-67, 2011.

BATANERO, Carmen. Los retos de la cultura estadística. Conferencia en las Jornadas Interamericanasde Enseñanza de la Estadística, Buenos Aires.

Confederación Latino-americana de Sociedades de Estadística, (2002). 
BRASIL. Parâmetros Curriculares Nacionais: Matemática /Secretaria de Educação Fundamental. Brasília: MEC/SEF, 1998. Disponível em:

$<\mathrm{http}$ ://portal.mec.gov.br/seb/arquivos/pdf/matematica.pdf>. Acesso em: 04 fev. 2021.

BRASIL. Ministério da Educação; Secretaria da Educação Básica, Brasília, DF: MEC/SEB, 2019. Base Nacional Comum Curricular. Disponível em: $<$ http://basenacionalcomum.mec.gov.br/wpcontent/uploads/2018/12/BNCC 19dez20 18 site.pdf >. Acesso em: 17 jun. 2019.

CAZORLA, Irene Mauricio; OLIVEIRA, Marcelo Silva de. Para saber mais. In: CAZORLA, Irene Mauricio; SANTANA, Eurivalda (Orgs.). Do tratamento da informação ao letramento estatístico. Itabuna: Via Litterarum, 2010. Cap. 1, p. 918.

CAZORLA, Irene; MAGINA, Sandra; GITIRANA, Verônica e GUIMARÃES, Gilda (Org.). Estatística para os Anos Iniciais do Ensino Fundamental. Sociedade Brasileira de Educação Matemática, Biblioteca do Educador - Coleção SBEM; 9 , Brasília: 2017.

COUTINHO, Cileda; SPINA, Gabriela. A Estatística nos Livros Didáticos de Ensino Médio. Ensino da Matemática em Debate. v 2, n 2. 2015 Disponível em < https://revistas.pucsp.br/emd/article/view/26219/18876>. Acesso em: 01 fev. 2020.

GAL, Iddo. Adults' Statistical Literacy: Meanings, Components, Responsibilities. In: International Statistical Review. Israel, 2002. p. 1-25. Disponível em: http://iaseweb.org/documents/intstatreview/02.Gal.pdf . Acesso em: 14 mar. 2019.

SANTANA, Eurivalda Ribeiro dos Santos; LAUTERT, Sintria Lautert; CASTRO FILHO, José Aires; SANTOS, Ernani Martins. Observatório da Educação em Rede: As Estruturas Multiplicativas e a Formação Continuada. Educação Matemática em Foco (UEPB), v. V, p. 77-95, 2016.

SANTANA, Eurivalda Ribeiro dos Santos; CARZOLA, Irene Mauricio; SANTOS, Ernani Martins Desempenho de estudantes do ensino fundamental em situações de estruturas multiplicativas. Revista Paranaense de Educação Matemática, v. 8, p. 147-147, 2019.

SOUZA, Leandro de Oliveira; LOPES, Celi Espasandin; SOUZA, Antônio Carlos. Os Delineamentos Metodológicos nas Investigações Brasileiras em Educação Estatística. Perspectivas da Educação Matemática. v. 8, n. 18, p. 506-525, 18 dez. 2015.

TRIOLA, Mario F. Introdução à Estatística. Rio de Janeiro: LTC, 2005.

WAINER, Howard. A study of Display Methods for NAEP Results: I. Tables. Program Statistics Research. Technical: Report no 95, 1. Educacional Testing Service.

Princeton, 1995. Disponível em:

https://onlinelibrary.wiley.com/doi/epdf/10.1002/j.2333-8504.1995.tb01645.x .

Acesso em: 16 de março de 2019.

WILD, Chris. J.; PFANNKUCH, Maxine. Statistical Thinking in Empirical Enquiry. International Statistical Review, 67(3), p. 223-265, 1999.

YIN, Robert K. Pesquisa qualitativa do início ao fim. Porto Alegre: Penso, 2016. 
Submetido em maio de 2021.

Aceito em outubro de 2021.

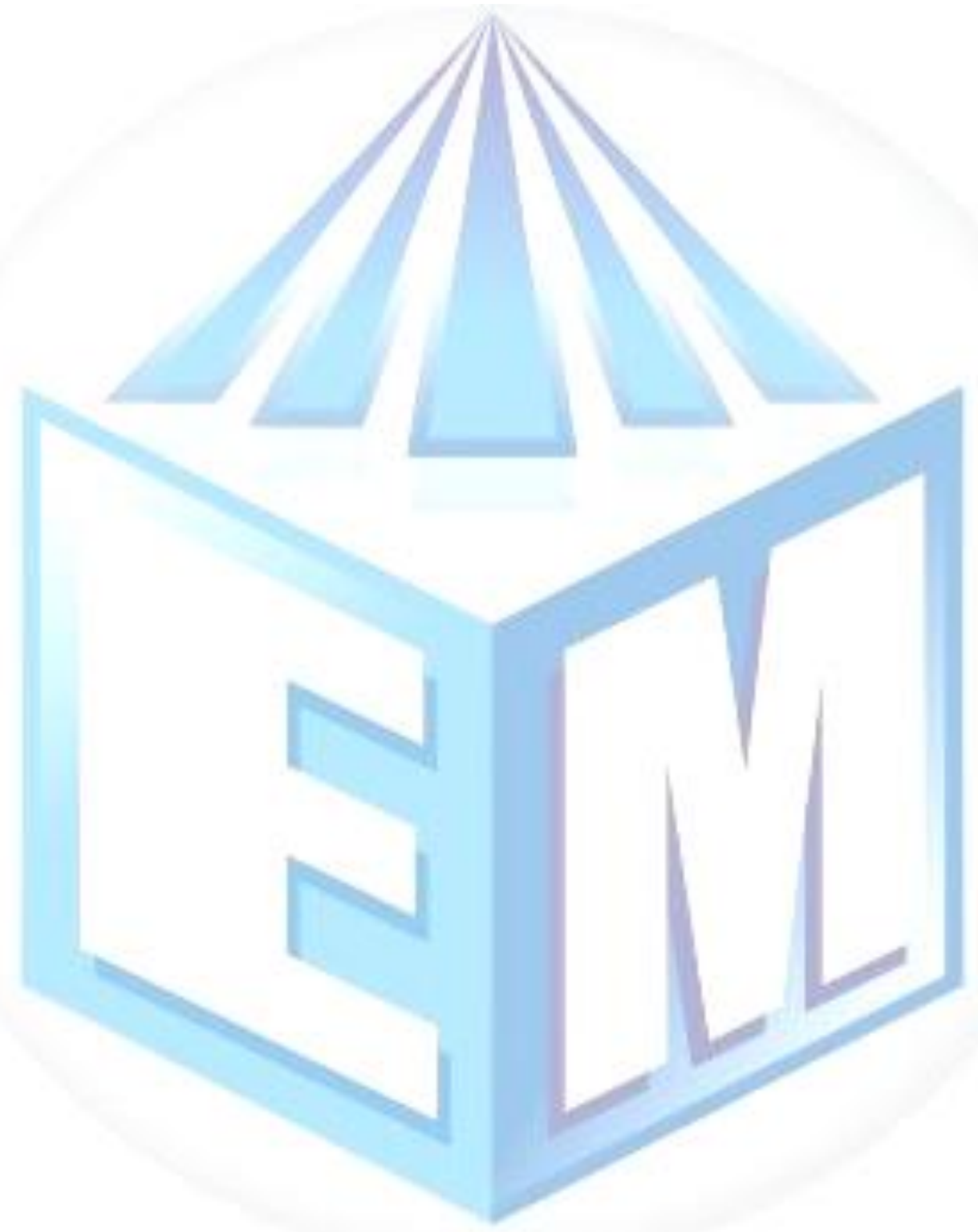

Perspectivas da Educação Matemática - INMA/UFMS - v. 14, n. 36 - Ano 2021 